\title{
Functional Bi Coatings as A Perspective Material for Radiation Shields Production against Electron Radiation
}

\author{
Daria I. Tishkevich ${ }^{1,2, *}$, Sergey S. Grabchikov' ${ }^{1}$ Stanislav B. Lastovskii', Dzmitry V. Yakimchuk', \\ Denis A. Vinnik², Alla I. Vorobjova ${ }^{3}$, Tatiana I. Zubar ${ }^{1,2}$, Alex V. Trukhanov ${ }^{1,2}$ \\ ${ }^{1}$ Laboratory of Magnetic Films Physics, Laboratory of Radiation Influences, Division of Cryogenic Research, SSPA \\ "Scientific-Practical Materials Research Centre of NAS of Belarus", P. Brovki str. 19, Minsk, 220072, Belarus \\ 2Laboratory of Single Crystal Growth, South Ural State University, Lenin ave. 76, Chelyabinsk, 454080, Russia \\ ${ }^{3}$ Laboratory of Hybrid Microcircuit Technology, Belarusian State University of Informatics and Radioelectronics, \\ P. Brovki str. 6, Minsk, 220013, Belarus
}

*Corresponding author: E-mail: dashachushkova@gmail.com, Tel.: (+375) 295628187

DOI: $10.5185 /$ amlett.2020.021479

Currently, medicine uses a large number of devices and sources of ionizing radiation, which have a dangerous effect on workers in medical diagnostic rooms and patients. Human organs are very sensitive to the damaging effects of radiation. The commonly used material for radiation protection proposes is lead. In recent years, bismuth deposition has become an interesting subject for the electrochemical community because of its unique properties. There are a limited number of authors dealing with $\mathrm{Bi}$ films onto metallic substrates by electrochemical deposition. The conditions of $\mathrm{Bi}$ electrodeposition and the structure of $\mathrm{Bi}$ coatings were examined. The shielding efficiency of $\mathrm{Bi}$ coatings under electron irradiation with 1,6-1,8 MeV was measured. The electron beam attenuation coefficient was estimated by the changing of current-voltage characteristics of semiconductor test structures which were located with and without shields. It has been determined that optimal shielding efficiency and mass-dimensional parameters have Bi shields with $2 \mathrm{~g} / \mathrm{cm}^{2}$ mass thickness and 156 shielding efficiency.

\section{Introduction}

Currently, medicine uses a wide range of ionizing radiation as a diagnostic method for human internal organs studying. The magnetic resonance imaging (MRI) method and positron emission tomography (PET) are actively developing diagnostic and research tools in nuclear medicine. The PET method is the ability to track the biologically active compounds distribution in the body labeled with positron-emitting radioisotopes [1] using a special detection equipment (PET scanner). For example, a single use of the most popular labeled compound (radiopharmaceutical 18F-FDG) for PET neuroimaging and treatment of cancer patients creates an effective radiation dose of $14 \mathrm{mSv}$. For comparison, the maximum year dose for nuclear power plant workers can reach 50 $\mathrm{mSv}$. The main damaging factor is gamma radiation, which occurs when positrons are annihilated with electrons. For effective gamma shielding with MRI-PET diagnostics, the main requirements for materials [1] were identified: limited conductivity compatibility; limited magnetic compatibility; a high mass attenuation coefficient $(d / \rho$, where $d-$ is the material thickness; $\rho-$ is the material density); high material density.

Another equally important method for the study of human internal organs is the computed tomography (CT).
This method is based on the measurement and computer processing of the difference in attenuation of X-rays by different tissues. At present days, X-ray CT is the main tomographic method for studying the internal organs of a person using X-ray radiation. However, during computed tomography the frequency of DNA damage increases. In the CT process, the radiation dose was 120 times higher than with a single X-ray chest examination [2].

Currently, a large variety of materials is used for protection against damaging influence of ionizing radiation. Such materials as aluminum, copper, tungsten, lead and etc. are used to protect against electron, X-ray, gamma radiation. Heavy elements are commonly used to effectively absorb high-energy radiation. The most widely used heavy material is lead, but it is a toxic metal.

Nowadays, Bi electrochemical deposition has become an attractive subject for the electrochemical community because of its unique properties. Bi has found application in electroanalytical chemistry as a new promising environmentally safe electrode in place of a poisonous mercury dropping electrode [3]. Uses of Bi-based composites offer a very good alternative to lead protection from gamma radiation due to the much more environmentally friendly $\mathrm{Bi}[4] . \mathrm{Bi}_{2} \mathrm{O}_{3}$ glasses are used as gamma radiation shields [5] and textile materials with $\mathrm{Bi}_{2} \mathrm{O}_{3}$ particles are applied in the overalls manufacture for 


\section{Advanced Materials Letters www. vbripress.com/aml}

medical personnel working on X-ray and gamma-ray systems [6]. Multilayer structures with light ( $\mathrm{Sn}, \mathrm{Sb}, \mathrm{Ba}$ ) and heavy ( $\mathrm{W}$ and $\mathrm{Bi}$ ) elements on the polymer substrate provides a weakening equivalent to the case of pure lead, yet with mass dimensions lower by $25 \%$ [7]. There is a limited number of authors dealing with deposition of $\mathrm{Bi}$ films onto metallic substrates by electrochemical deposition $[8,9]$. It is noteworthy that the number of articles devoted to the obtaining of functional materials by electrochemical deposition increases due to the large number of advantages of this method [10-14].

The problem of protection against ionizing radiation is especially acute during CT diagnostic of the mammary and thyroid glands, since they are very radiation-sensitive to X-rays. In [15-17], methods for Bi protection obtaining were studied and the main operational characteristics were revealed. It is shown that these shields have a high efficiency $-30 \%$ or more. The authors of [18] conclude that, despite the technical nuances of Bi shields using, they still remain the best candidates for protection against $\mathrm{X}$ rays.

It is important that for an effective radiation protection creating, the thickness of the shielding materials should be about $1 \mathrm{~mm}$ or more. In this connection, the present work tasks are to develop electrochemical deposition regimes for the $\mathrm{Bi}$ coatings synthesis with 100-2700 $\mu \mathrm{m}$ thick and to study their structure and shielding efficiency against ionizing radiation.

\section{Experimental}

Samples of Bi coatings were electrochemically deposited from an acid perchlorate electrolyte. Electrolyte was prepared from perchloric acid solution $(400 \mathrm{ml} / \mathrm{l})$ and bismuth (III) oxide $(40 \mathrm{~g} / \mathrm{l})$. Bismuth deposition was carried out in galvanostatic regime onto $\mathrm{Al}$ substrates with $0.4 \mathrm{~mm}$ thickness. The current density was $100 \mathrm{~mA} / \mathrm{cm}^{2}$. $\mathrm{Bi}$ rods were used as anodes. Organic additive - gelatin was added into the electrolyte at $0.1-0.5 \mathrm{~g} / \mathrm{l}$ concentration. $\mathrm{Cu}$ electrodeposition was carried out before $\mathrm{Bi}$ deposition. Electrodeposition of $\mathrm{Cu}$ sublayer was performed in electrolyte of the following composition: $\mathrm{CuSO}_{4}-35 \mathrm{~g} / \mathrm{l}$, $\mathrm{K}_{4} \mathrm{P}_{2} \mathrm{O}_{7}-145 \mathrm{~g} / \mathrm{l}, \mathrm{Na}_{2} \mathrm{HPO}_{4}-95 \mathrm{~g} / \mathrm{l}, \mathrm{KNa}$ tartrate $-25 \mathrm{~g} / \mathrm{l}$ $\left(\mathrm{pH} 8.5, \mathrm{~T}=32-35^{\circ} \mathrm{C}\right.$, current density $\left.-10 \mathrm{~mA} / \mathrm{cm}^{2}\right)$. The electrodeposition experiments were performed using B678/6 power source. The Bi coatings mass thickness was calculated using:

where $\rho_{\mathrm{Bi}}-$ Bi density.

$$
\mathrm{d}_{\text {mass }}=\mathrm{d} \times \rho_{\mathrm{Bi}},
$$

The investigation of Bi coatings surface morphology was realized on scanning electronic microscope (SEM) LEO 1455VP. X-ray diffraction (XRD) analysis of Bi coatings was performed on a PanAnalytical Empyrean diffractometer using monochromatized $\mathrm{CuK} \alpha$ irradiation $(\lambda=0.154 \mathrm{~nm})$.

Samples irradiation using a linear electron accelerator ELA-4 was carried out. After the output window the nominal electron energy was $4 \mathrm{MeV}$, the fluence was
$(1 \div 50) \cdot 10^{13} \mathrm{~cm}^{-2}$. The electron beam density was $4 \cdot 10^{11} \mathrm{~cm}^{-2} \mathrm{~s}^{-1}$ and was controlled by a Faraday cylinder. It is known [5], that the attenuation coefficient by the substance irradiation depends on the energy spectrum. A duralumin plate with $5 \mathrm{~mm}$ thickness was placed between the electron window output and target to reduce electron energy from $4 \mathrm{MeV}$ to $1.6-1.8 \mathrm{MeV}$.

After duralumin shield the electron beam with $1.6-1.8 \mathrm{MeV}$ energy and concomitant braking radiation is directed to the investigated $\mathrm{Bi}$ shield. The test sample was located after the radiation shield. The shielding efficiency was evaluated by estimating the behavior of the voltampere characteristics of test p-MOS transistors. The method of determining the radiation absorbed dose is based on a changing in radiation-sensitive parameters of p-MOS transistors is quite convenient from the point of view of practical application [6]. The measurements of the drain-gate characteristics of the test p-MOS transistors were carried out before and after each dose on the MISD$1 / 6$ measuring equipment for semiconductor devices.

Radiation changes in the p-MOS transistors characteristics are due to, firstly, with the scavenging of free charge carriers in deep centers in the dielectric bulk and, secondly, with the surface states formation at the dielectric-semiconductor interface. The scavenging of the charge carriers in the $\mathrm{SiO}_{2}$ bulk causes a shift in the threshold voltage. The increasing in the surface states density leads to decreasing in the slope of the drain-gate characteristics. The absorbed dose was determined from the changing in the threshold voltage $\operatorname{drop}(\Delta \mathrm{U})$ at leakage currents Ic $=10^{-7} \mathrm{~A}$ for $\mathrm{p}$-MOS transistors. The shielding efficiency was evaluated from the changing of threshold voltage for the p-MOS transistors located after shield and without shield. The shielding efficiency (coefficient) values were calculated from the ratio (2):

$$
\mathrm{E}_{\text {shild }}=\mathrm{F} / \mathrm{F}_{0} \text {, }
$$

where $\mathrm{F}$ - the electron fluence corresponding to a parametric failure of a shielded p-MOS transistor;

$\mathrm{F}_{0}$ - the electron fluence corresponding to a parametric failure of unshielded p-MOS transistor.

The parametric failure was fixed with threshold voltage value $(\Delta \mathrm{U})$ is $0.05 \mathrm{~V}$.

\section{Results and discussion}

Fig. 1 shows the X-ray diffraction (XRD) spectra of $\mathrm{Bi}$ coatings with various thicknesses $(1-60 \mu \mathrm{m})$ obtained from an acid perchlorate electrolyte without organic additives. The number of reflexes increases with $\mathrm{Bi}$ coatings thickness rising. The reflexes intensity falls, this indicates about the grains formation with different orientations. According to XRD data, the structure of all Bi samples was characterized by the rhombohedral type of crystal lattice (space group R-3m). Bi coatings obtained from an electrolyte without additives have a pronounced texture (012). More detailed investigation of organic additives influence into electrolyte on the structure of $\mathrm{Bi}$ coatings is shown in [19]. 


\section{Advanced}

Materials Letters

www. vbripress.com/aml

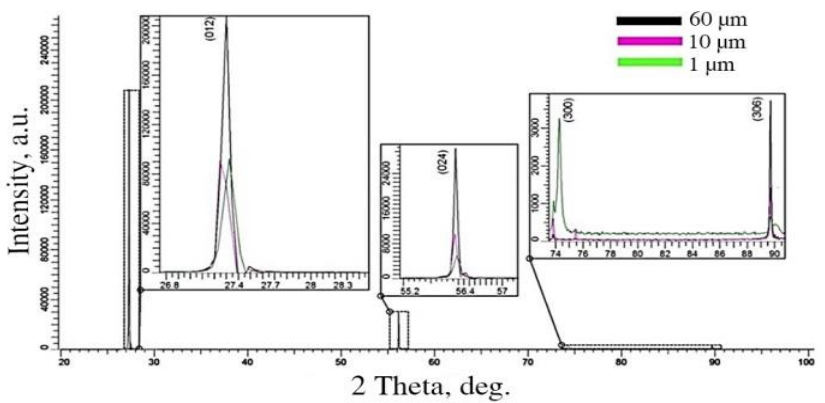

Fig. 1. XRD spectra of Bi coatings with 1,10 and $60 \mu \mathrm{m}$ thicknesses.

The phase composition of $\mathrm{Bi}$ coatings was obtained and the main parameters of the crystal lattice were calculated (Table 1). It can be seen from the table that, with the $\mathrm{Bi}$ coatings thickness increasing the cell parameter a - grows, and the parameter c - decreases. This behavior of the cell parameters is associated with an anisotropic change in the shape of the crystal lattice.

Table 1. Structural characteristics of Bi coatings.

\begin{tabular}{|c|c|c|c|c|}
\hline Composition & (hkl) & $\begin{array}{c}\text { Angle, } \\
2^{\circ}\end{array}$ & 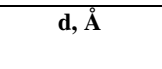 & $\begin{array}{c}\text { Cell } \\
\text { parameter, } \AA\end{array}$ \\
\hline \multirow{3}{*}{$\begin{array}{c}\mathbf{B i} \\
\mathrm{d}=1 \mu \mathrm{m}\end{array}$} & 012 & 27.321 & $3.2616 \pm 0.0003$ & \multirow{3}{*}{$\begin{array}{l}a=4.4364 \\
c=12.3415\end{array}$} \\
\hline & 024 & 56.170 & $1.6362 \pm 0.0003$ & \\
\hline & 300 & 74.257 & $1.2761 \pm 0.0003$ & \\
\hline \multirow{3}{*}{$\begin{array}{c}\mathrm{Bi} \\
\mathrm{d}=\mathbf{1 0} \mu \mathrm{m}\end{array}$} & 012 & 27.251 & $3.2698 \pm 0.0003$ & \multirow{3}{*}{$\begin{array}{l}\mathrm{a}=4.4821 \\
\mathrm{c}=12.1219\end{array}$} \\
\hline & 024 & 56.138 & $1.6370 \pm 0.0003$ & \\
\hline & 300 & 89.692 & $1.0923 \pm 0.0003$ & \\
\hline \multirow{3}{*}{$\begin{array}{c}\mathbf{B i} \\
\mathbf{d}=\mathbf{6 0} \mu \mathrm{m}\end{array}$} & 012 & 27.302 & $3.2639 \pm 0.0003$ & \multirow{3}{*}{$\begin{array}{l}\mathrm{a}=4.5158 \\
\mathrm{c}=11.8651\end{array}$} \\
\hline & 024 & 56.144 & $1.6369 \pm 0.0003$ & \\
\hline & 306 & 89.679 & $1.0924 \pm 0.0003$ & \\
\hline
\end{tabular}

As can be seen from the SEM images presented in Fig. 2 the Bi coatings with $1 \mu \mathrm{m}$ thickness have a finegrained structure with $0.58 \mu \mathrm{m}$ the most possible grain size. As Bi thickness increases to $60 \mu \mathrm{m}$, the grain size increases and becomes $7.99 \mu \mathrm{m}$. Apparently this is due to the growth mechanism of grains. At the initial stages of growth, the process of nucleation predominates, at the subsequent stages, the unification and growth of grains prevails.
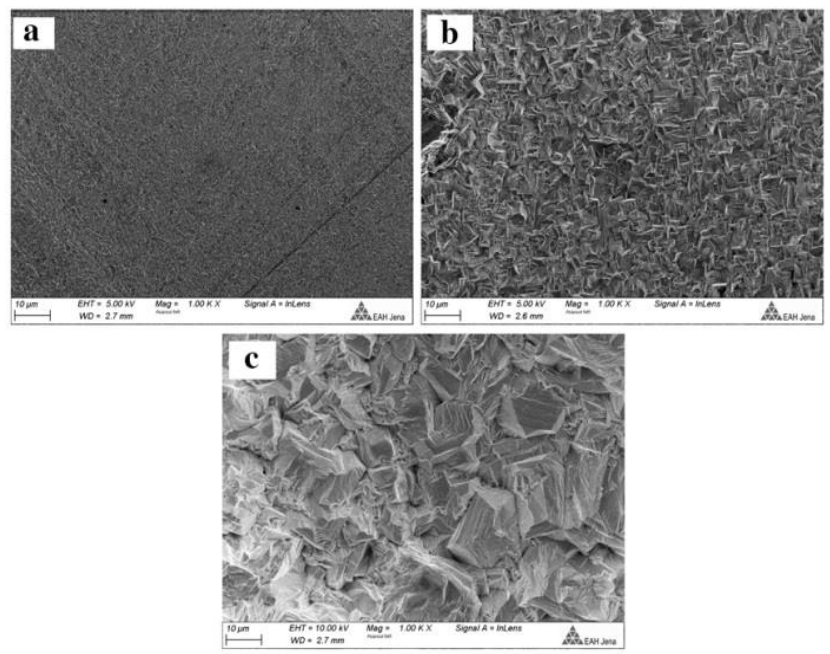

Fig. 2. SEM images of the Bi coating surface with $1 \mu \mathrm{m}(\mathrm{a}), 10 \mu \mathrm{m}$ (b) and $60 \mu \mathrm{m}$ (c) thicknesses obtained from an electrolyte without additives.
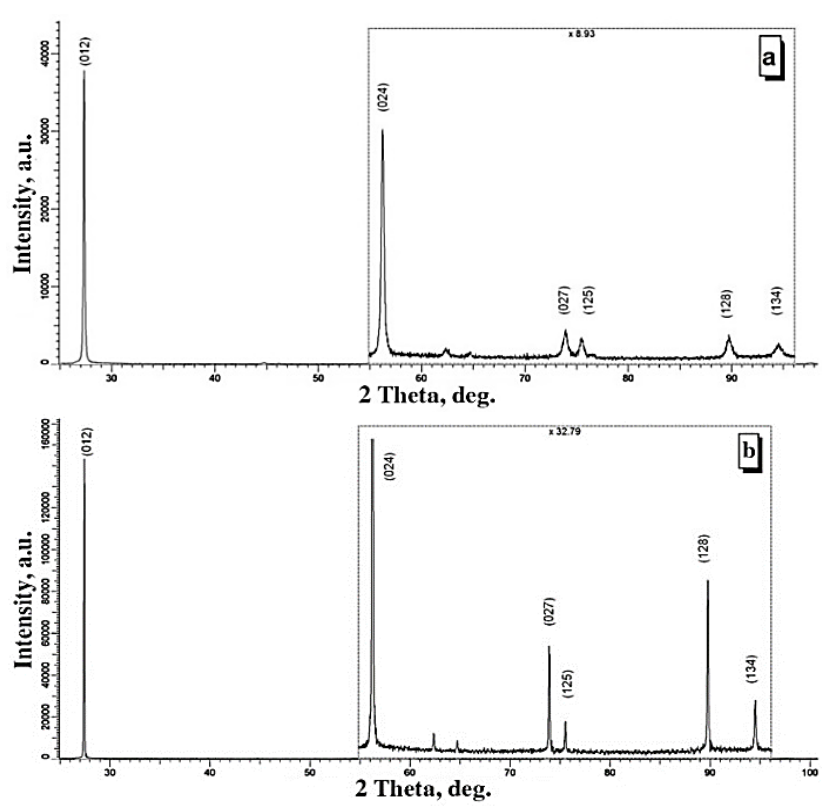

Fig. 3. XRD patterns of Bi coatings $(300 \mu \mathrm{m})$ electrodeposited from an electrolyte with $0.5 \mathrm{~g} / \mathrm{l}$ gelatin concentration (a) and without it (b).

Fig. 3. shows the XRD data of Bi coatings obtained from electrolyte with gelatin adding. Such Bi coatings have a rhombohedral type of crystal lattice (space group $\mathrm{R}-3 \mathrm{~m}$ ) with lattice parameters: $\mathrm{a}=4.52 \AA$ and $\mathrm{c}=11.80 \AA$. Grain size changes downward, new peaks do not arise, however, their intensity decreases and reflexes become wider.

Fig. 4 shows SEM images of Bi coatings obtained in an electrolyte with the addition of gelatin at $0.1-0.5 \mathrm{~g} / 1$ concentration. It was noted that the average crystallite size decreases from 1.9-8.3 $\mu \mathrm{m}$ to $0.78-1.1 \mu \mathrm{m}$. A decrease in the average grain size is apparently associated with the formation of stable adsorbed gelatin cation-organic complexes with Bi ions, which, in turn, contributes to an increase in cathodic polarization.
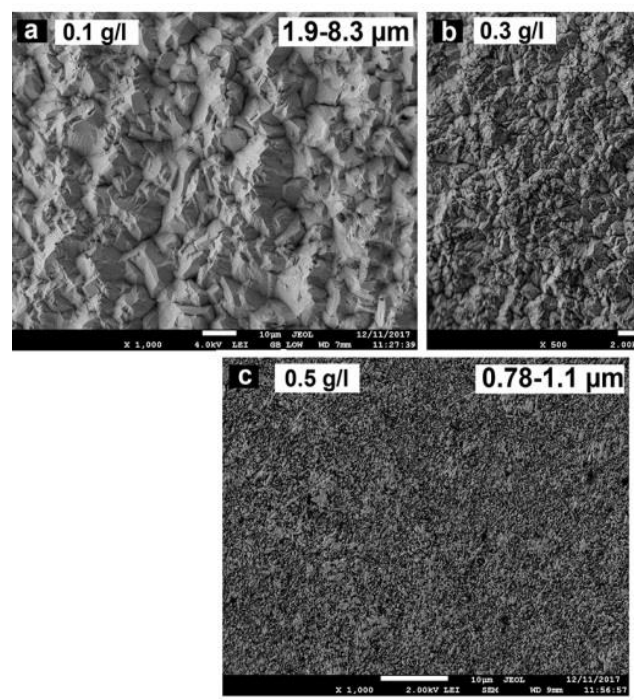

Fig. 4. SEM images of Bi coatings surface $(300 \mu \mathrm{m})$ obtained from an electrolyte with gelatin $0.1 \mathrm{~g} / \mathrm{l}$ (a), $0.3 \mathrm{~g} / 1$ (b), $0.5 \mathrm{~g} / \mathrm{l}$ (c). 


\section{Advanced Materials Letters www. vbripress.com/aml}

A partial positive charge formed on the nitrogen atom $\left(-\mathrm{NH}^{3+}\right)$ promotes passivation of the cathode surface, which is a source of electrons and prevents the growth of grains and leads to the formation of a fine-grained structure. The carboxy group (-COO-) promotes the nucleation of new crystallization centers by adsorption of $\mathrm{Bi}^{3+}$ ions on the unsaturated bonds $-\mathrm{COO}-\ldots \mathrm{Bi}^{3}+\ldots-$ COO-. Gelatin interaction is mainly related to its strong adsorption at the metal-solution interface. The intensity of diffraction peaks is different for samples obtained in an electrolyte without additives and with the addition of gelatin, which indicates a change in grains size and lattice deformation in the additive presence.

The drain-gate characteristics of electron irradiated test p-MOS transistors shift to negative values when the radiation dose increases. The charge carriers capture in the $\mathrm{SiO}_{2}$ volume and on the surface states levels causes a shift in the threshold voltages. Surface state density increasing leads to an additional scattering of mobile charge carriers and decreasing in the drain-gate steepness of p-MOS transistors characteristics. The p-MOS transistors leakage current rising with fluence increasing.

Fig. 5(a) shows the dependence of threshold voltage shift $\Delta \mathrm{U}$ on the electron radiation fluence of the p-MOS transistors, which is not protected by shield. The electron fluence was determined at which a parametric failure of unprotected p-MOS transistor occurs from the obtained results. The fixed value of the parametric failure $(0.05 \mathrm{~V})$ corresponds to an electron fluence of order $\mathrm{F}_{0}=2.3 \cdot 10^{12} \mathrm{~cm}^{-2}$.
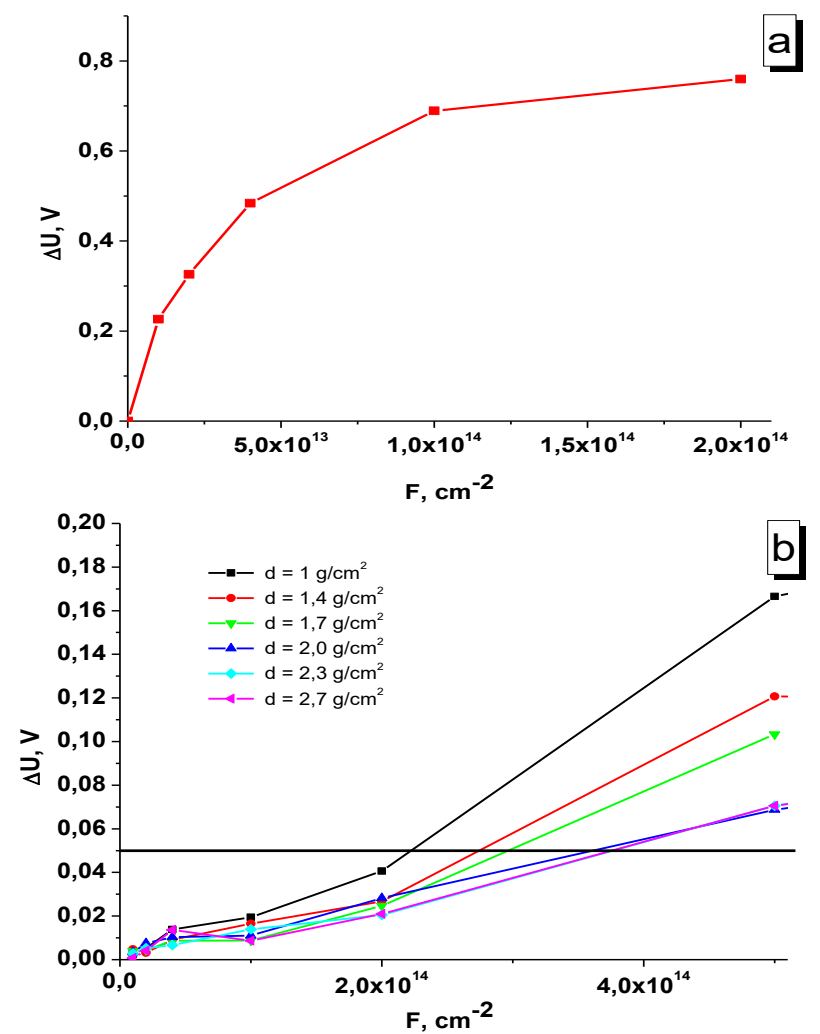

Fig. 5. p-MOS transistors threshold voltage changing under the electron radiation without shield (a) and with Bi shields with different mass thicknesses (b).
Fig. 4(b) shows the threshold voltage shift dependence of electron irradiated p-MOST protected by $\mathrm{Bi}$ shield. The increasing of $\Delta \mathrm{U}$ for all shielded MOSTs is observed in the all entire investigated range of electron irradiation fluences. However, for the same electron fluence values, the changes in the threshold voltage are significantly smaller for protected samples compared to unprotected samples. This effect is enhanced with thickness increasing of the $\mathrm{Bi}$ shield. From the results presented in Fig. 5(b), it follows that all shields have sufficiently high values of shielding efficiency. The calculations result of the $\mathrm{E}_{\text {shield }}$ values of $\mathrm{Bi}$ shields with different mass thicknesses are given in the Table 2 .

Table 2. The electron fluence corresponding to the parametric failure of the p-MOS transistors, and the shielding efficiency of Bi shields with different mass thicknesses.

\begin{tabular}{c|c|c|c}
\hline Shield № & $\begin{array}{c}\text { Mass thickness } \\
{\left[\mathbf{d}_{\text {mass }}\right], \mathbf{g} / \mathbf{c m}^{\mathbf{2}}}\end{array}$ & $\begin{array}{c}\text { Fluence [F], } \mathbf{c m}^{-} \\
\mathbf{E}_{\text {shield, }} \\
\mathbf{F}_{\mathbf{F}}\end{array}$ \\
\hline 1 & 1,0 & $2,2 \cdot 10^{14}$ & 95 \\
\hline 2 & 1,4 & $2,7 \cdot 10^{14}$ & 117 \\
\hline 3 & 1,7 & $3,0 \cdot 10^{14}$ & 130 \\
\hline 4 & 2,0 & $3,6 \cdot 10^{14}$ & 156 \\
\hline 5 & 2,3 & $3,8 \cdot 10^{14}$ & 162 \\
\hline 6 & 2,7 & $3,8 \cdot 10^{14}$ & 165 \\
\hline
\end{tabular}

As can be seen from the data in the Table 2, the $\mathrm{E}_{\text {shied }}$ values increase with the shields mass thickness rising. In this case, the $\mathrm{Bi}$ shields thickness increasing to the values $\mathrm{d}_{\text {mass }}=2.0 \mathrm{~g} / \mathrm{cm}^{2}$ is more strongly affects in the $E_{\text {shied }}$ changing, than at $\mathrm{E}_{\text {shied }}>2.0 \mathrm{~g} / \mathrm{cm}^{2}$.

It has been shown that at shield thickness $\mathrm{d}_{\text {mass }}=1.7$ $\mathrm{g} / \mathrm{cm}^{2}$, the dose accumulated by the sample is reduced in $\mathrm{E}_{\text {shied }}=130$ times. The excessive Bi thickness build-up does not give a clear advantage in the shielding efficiency. It can be concluded that shields with $\mathrm{Bi}$ thicknesses of the 1.7-2.0 $\mathrm{g} / \mathrm{cm}^{2}$ order are the most optimal for protection against electron radiation from the point of view of massdimensions parameters. The nature of the $E_{\text {shied }}\left(d_{\text {mass }}\right)$ dependences is due to the electron interaction and braking radiation with shields material. All electrons are scattered by the shield material with the Bi shields mass thickness $\mathrm{d}_{\text {mass }}=2.0 \mathrm{~g} / \mathrm{cm}^{2}$. In this case, and for $\mathrm{d}_{\text {mass }}>2.0 \mathrm{~g} / \mathrm{cm}^{2}$ the secondary types of radiation contribute to the absorbed dose (braking radiation). This radiation has a high penetrating power.

\section{Conclusion}

The electrochemical deposition conditions and Bi coatings structure were examined. X-ray diffraction patterns for all samples were indexed to rhombohedral $\mathrm{Bi}$. The organic additive - gelatin adding leads to the growth Bi texture with different orientation. The shielding efficiency of $\mathrm{Bi}$ shields under 1,6-1,8 MeV electron irradiation was measured. It has been determined that optimal shielding efficiency and mass-dimensional parameters have $\mathrm{Bi}$ shields with 1,6-2.0 $\mathrm{g} / \mathrm{cm}^{2}$ mass thickness and 130-156 attenuation coefficient. It has been shown that $\mathrm{Bi}$ shields 


\section{Advanced Materials Letters www. vbripress.com/aml}

thickness increasing more than $2 \mathrm{~g} / \mathrm{cm}^{2}$ does not lead to a significant rising in shielding properties, which is due to the predominant contribution to the shield absorbed dose of braking radiation.

\section{Acknowledgements}

The work was carried out with financial support of Belarusian Republican Foundation for Fundamental Research (Grant No. Ф18Д007) and partially supported by the Grant of Wold Federation of Scientists (Geneva, Switzerland).

\section{Author's contributions}

Conceived the plan: D.I. Tishkevich, S.S. Grabchikov, S.B. Lastovskii; Performed the expeirments: D.V. Yakimchuk, T.I. Zubar, A.V. Trukhanov, A.I. Vorobjova, A.L. Kozlovskiy, M.V. Zdorovets; Data analysis: D.I. Tishkevich, S.S. Grabchikov, D.A. Vinnik; Wrote the paper: D.I. Tishkevich, A.V. Trukhanov. Authors have no competing financial interests.

\section{Keywords}

Electrochemical deposition, bismuth, shielding, electron radiation, semiconductor structures.

Received: 09 August 2019

Revised: 24 November 2019

Accepted: 25 November 2019

\section{References}

1. Schenck, J.F.; Med. Phys., 1996, 23, 815 .

2. Stanford University Medical Center, DNA damage seen in patients undergoing CT scanning, study finds / Stanford University Medical Center // ScienceDaily - Standfort http//www.sciencedaily.com/releases/2015/07/150722144634.htm.

3. Tishkevich, D.I.; Grabchikov, S.S.; Lastovskii, S.B.; Trukhanov, S.V.; Zubar, T.I.; Vasin, D.S.; Trukhanov, A.V.; Kozlovskiy, A.L.; Zdorovets, M.V.; ACS Applied Energy Materials, 2018, 1, 1695.

4. Ziegler, J.P.; Solar Energy Mater Solar Cells, 1999, 56, 477.

5. DeTorresi, S.I.C.; Carlos, I.A.; J. Electroanal. Chem., 1996, 414, 11 .

6. Jeong, S. Yu.; Choi, K.S.; Shin, H.; Kim, T.L.; Song, J.; Yoon, S.; Jang, H.W.; Yoon, M. H.; Jeon, Ch.; Lee, J.; Lee, S.; ACS Appl. Mater. Interfaces, 2017, 9, 505.

7. Yang, F.Y.; Science, 1999, 284, 1335.

8. Jin, Q.; Shi, W.; Zhao, Ya.; Qiao, J.; Qui, J.; Sun, Ch.; Lei, H.; Jiang, X.; ACS Appl. Mater. Interfaces, 2018, 10, 1743.

9. McCaffrey, J. P.; Mainegra-Hing, E.; Shen, H.; Med. Phys. J., 2009, 36, 5586.

10. Tishkevich, D.I.; Grabchikov, S.S.; Lastovskii, S.B.; Trukhanov, S.V.; Zubar, T.I.; Vasin, D.S.; Trukhanov, A.V.; Journal of Alloys and Compounds, 2018, 749, 1036.

11. Tishkevich, D.I.; Vorobjova, A.I.; Vinnik, D.A.; Materials Science Forum, 2019, 946, 235.

12. Zubar, T.I.; Fedosyuk, V.M.; Trukhanov, A.V.; Kovaleva, N.N.; Astapovich, K.A.; Vinnik, D.A.; Trukhanova, E.L.; Kozlovskiy, A.L.; Zdorovets, M.V.; Solobai, A.A.; Tishkevich, D.I.; Trukhanov S.V.; Journal of the Electrochemical Society, 2019, 166 (6), D173.

13. Tishkevich, D.I.; Vorobjova, A.I.; Shimanovich, D.L.; Vinnik, T D.A.; Zubar, T.I.; Kozlovskiy, A.L.; Zdorovets, M.V.; Yakimchuk, D.V.; Trukhanov, S.V.; Trukhanov A.V.; Journal of Alloys and Compounds, 2019, 804, 139.

14. Vorobjova, A.I.; Shimanovich, D.L.; Sycheva, O.A.; Ezovitova, T.I.; Tishkevich, D.I.; Trykhanov, A.V.; Russian Microelectronics, 2019, 48, 107.

15. McCollough, C.; Wang, J.; Gould, R.; Orton, C.; Med. Phys., 2012, 39, 2321.

16. Mendes, M.; Costa, F.; Figueira, P.; Teles, P.; Vaz, P.; Radiation protection dosimetry, 2015, 165, 175.

17 Kim, S.; Yoshizumi, T.T.; Frush, D.P.; Anderson-Evans, C.; Toncheva, G.; Radiation protection dosimetry, 2009, 113, 105.

18. Morford, K.; Watts, L.; Radiology management, 2012, 34, 45.
19. Tishkevich, D. I.; Grabchikov, S. S.; Tsybulskaya, L. S.; Shendyukov, V. S.; Perevoznikov, S. S.; Trukhanov, S. V.; Trukhanova, E. L.; Trukhanov, A. V.; Vinnik, D. A.; Journal of Alloys and Compounds, 2018, 735, 1943. 